\title{
The Nature of Scientific and Other Hypotheses
}

\author{
BY DR. E. C. OWEN \\ Hannah Dairy Research Institute, Kirkhill, Ayr, Scotland \\ ABSTRACT of Paper read on 16th January, 1950
}

Philosophy is knowledge gained by the analysis of knowledge, or by the re-synthesis of the products of such analysis. Knowledge is derived by two processes, perception of externality, and introspection.

Facts are products of perceptions stored in the memory, and may be either public or private.

Public facts are scientific, legal or historic. Historic facts depend upon memories of people already dead. Legal facts depend upon the memories of the living. Scientific facts have both these characteristics and in addition are demonstrable at will to any intelligent audience. Facts, in general, have a scientific, a legal and a historic aspect.

Scientific facts are physical, chemical or biological. The facts of biology are about living things. Physics is concerned with the properties common to all things, chemistry with the way in which properties change from thing to thing.

Private facts are those which are known for certain only by the individual. My belief that other people's minds contain private facts is based on analogy with my own private facts and on my belief in behaviouristic psychology. Private facts have a cognitive, an affective and a conative aspect.

All facts are products of experience and, being the basis of our actions, are built into some sort of philosophic system by each of us. This process of building may be called creation in the same sense as the word is used of art. Facts, once stored in the memory, are systematised by ideas (concepts) supplied by the mind itself. Of supreme importance among these concepts are hypotheses. By means of these, both public and private facts become logical deductions from hypotheses. Hypotheses are scientific, fantastic, ethical or abortive. Scientific (and perhaps the other) hypotheses may be quantitative, qualitative, or spatial. Deductions from qualitative or spatial hypotheses are made by logic; from quantitative ones by mathematics. Fantastic hypotheses are the basis of works of art and imagination. Ethical hypotheses are formulated in all religions and political creeds. Abortive hypotheses are those about which there is no consensus of intelligent opinion. There is a circle in mental development from facts to hypotheses and back to facts, but hypotheses are far less numerous than facts and they therefore lessen the burden on the memory.

The metrical side of mathematics is a product of counting, which is the conscious repetition of successive acts of attention, and is therefore psychological. Whatever the nature of the hypotheses induced by scientists to form a single coherent system of externality, it is a vain hope to think that any such system will stand the test of time, for sensuous entities cannot give accurate information about the supersensuous, and most hypotheses are statements of relations between supersensuous entities based on analogy with sensuous ones.

Science in the synoptic sense is not a static picture of the universe. It is merely an attempt to write a grammar of the universe. Analogy is the life blood of induction and without induction neither the world's favourite scientific theories nor its religious or political creeds would have been thought of. Confusion as to the nature of induction has arisen because of the failure to distinguish between public and private facts and the consequent reluctance 
to admit the tentative nature of scientific hypotheses. Sciences should be taught inductively, i.e., with reference to the history of the mental processes and environments of its founders. Most hypotheses are private in origin but democratic in acceptance. The category of truth or falsity does not apply to hypotheses. It is therefore a fallacy to assume that all propositions must either be true or be false. In respect of truth and falsity there are (at least) the following classes of propositions.

1. Propositions about empirical public facts. A further appeal to experience can demonstrate the truth of these.

2. Propositions about historic facts whose truth is decided by the consensus of historical opinion.

3. Propositions about legal facts whose truth is decided by a court of law.

4. Propositions about private facts. As to the truth of these the individual is the sole judge.

5. Hypothetical propositions. These are all based on analogy and are therefore neither true nor untrue. They are either more or less convenient for the purpose in hand. Mathematical and geometric propositions belong here too, for metrical mathematics judges usefulness by the mutual consistency of statements made within a given conventional system, while geometric propositions are based on axioms and postulates the reliability of which is finally tested by experience.

\title{
Quantum Theory and Logic
}

\author{
BY DR. M. D. H. STRAUSS
}

ABSTRACT of Paper read on 20th February, 1950

The continued discussion about the so-called logical problems of quantum theory (QT) [cf., e.g., Reichenbach's book, recent issues of Dialectica and Philosophy of Science] is due to the absence of a recognized physical axiomatics to which these problems could be referred for settlement. The failure of various attempts to re-construct $\mathrm{QT}$ on the basis of simple physical postulates is a sign that a complete understanding of QT has not yet been achieved, or else that something entirely new is involved in such a reconstruction.

The reconstruction of the basic features of mathematical QT, carried out in 1936 by Dr. Strauss, $\S$ is based on what may be described as a translation of Bohr's conception of complementarity into the language of logical syntax where it gives rise to a new "logic" characterized by restricted sentential connectability. The main contentions of Dr. Strauss' lecture were (i) that this complementarity logic is absolutely essential in any rational reconstruction of QT, and (ii) that it accounts for the most general features of our experience in the field of quantum physics in exactly the same sense in which nonEuclidean geometry accounts for the basic feature of gravitation, i.e. the equivalence of gravitation and acceleration, or in which the Lorentz-transformation accounts for the basic fact in kinematics, viz., the existence of a finite limiting velocity.

The "most general feature of quantum physical experience" may be extracted either from an analysis of QT itself or from that of typical quantum phenomena. It consists (i) in the statistical character of all well-defined predictions, and (ii) in the relationship of general complementarity which holds between the results of any two actual measurements or observations (other than those of a constant quantity), and which may be stated thus : the results

§ Zur Begruendung der Statistischen Transformationstheorie der Quantenphysik,

Ber, Berl. Akad., phys,-math. Kl., Vol, XXVII (1936), 